Handwritten al phabet and di git char acter recognition usi ng feat ure extracting neural net work and modi fi ed sel f-or gani zi ng map

\begin{tabular}{|c|c|}
\hline 著者 & $\begin{array}{l}\text { Nakay ama Kenj i, Chi gawa Yasuhi de, Hasegawa } \\
\text { Osamu }\end{array}$ \\
\hline $\begin{array}{l}\text { jour nal or } \\
\text { publ i cati on } \mathrm{title} \text { e }\end{array}$ & I EEE\& NS Pr oc. I JCN' 92, Bal t i nor e \\
\hline vol une & $?$ \\
\hline page $r$ ange & $235-240$ \\
\hline year & 1992- 06- 01 \\
\hline URL & ht t p: //hdl . handl e. net /2297/6799 \\
\hline
\end{tabular}




\title{
HANDWRITTEN ALPHABET AND DIGIT CIIARACTER RECOGNITION USING FEATURE EXTRACTING NEURAL NETWORK AND MODIFIED SELF-ORGANIZING MAP
}

\author{
Kenji NAKAYAMA Yasuhide CHIGATA Osamu HASEGAWA \\ Dept. of Electrical and Computer Eng., Faculty of Tech., Kanazawa Univ. \\ 2-40-20, Kodatsuno, Kanazawa 920 Japan
}

\begin{abstract}
A new pattern recognition method is proposed for handwrltten alphabet and digit characters. Features, which include an end of a line, a corner, a junction polnt, a cross polnt, a line segment between the feature points, and an isolated circle, are employed to express relative topological structure of handwritten characters These features are extracted by mutually connected neural networks combined in a layer form. The feature polnt distribution of a standard pattern is mapped onto that of a distorted pattern, through a modlfled self-organizing map (SOM). The distorted pattern is recognized based on simllarlty between both feature point distributions. The modified SOM has the following advantages. First, the number of feature points is small, which are classifled Into several groups. Second, the mapplng is carrled out in the varlable ring shape reglon, in order to find out a suitable pairing of the feature points. Third, the feature points are selected from both the standard and the distorted patterns in order to avold any vibration. Finally, nelghborhood are selected along lines of the patterns. These improvements can provide stable and fast feature point mapping. Computer simulation demonstrates the proposed method can adapt a varlety of pattern distortions.
\end{abstract}

\section{INTRODUCTION}

Handwritten character recognition is very important application flelds of neural networks. Because, the conventional computers are not so good for this purpose. Neural networks are expected to do well due to their analogy to human brain information processing. It is, however, not so easy to simulate the human visual information process, due to a lack of enough knowledge. However, many approaches based on malnly artificlal neural networks have been proposed.

Neocognitron [1] is the first neural model, whlch can be applled to distorted pattern recognition. Recently, many approaches, based on multllayer neural networks, modifled back-propagation and self-organlzing methods have been proposed [2]-[6]. Some of them extract Invariant features in the handwritten characters through different methods from neural systems. The features are applled to pattern matching using neural networks. In another methods, the Input patterns are directly applled to the neural networks, in whlch feature extraction and pattern matching are simultaneously carrled out.

In this paper, we propose a new pattern recognition scheme [7] for handwritten alphabet and digit characters. Binary patterns are taken into account in this paper. A system consists of a feature extracting neural network and a modlfled self-organizing map (SOM). In order to express relative topological structure of handwritten characters, useful features are employed. Several improvements are introduced in order to effectlvely apply Kohonen's SOM [8] to handwritten character recognition. Computer simulation is demonstrated using alphabet and digit characters.

\section{INVARIANT FEATURES IN HANDWRITTEN CHARACTERS}

It is very important to extract features, which can express relative topological structure of handwritten characters. For this purpose, we employ the following features.

- End of a line

- Corner (Angle $\leqq 90$ degrees)

- Junction polnt (T type)

- Cross point ( + type)

- Arbitrary point on an isolated circle

- Middle point between another feature points

The middle polnt equivalently express a llne segment between two feature polnts. Flgure 1 shows examples of the feature points. A symbol $O$ is an inactive unit, and symbols $\bullet$, and is are active units. Furthermore, $\star$ and $s$ indicate the feature point and the middle point, respectively. 


\begin{tabular}{|c|c|c|c|c|c|c|}
\hline $\begin{array}{l}0000 \\
0 \star 00 \\
0000 \\
0.00 \\
\text { (a) }\end{array}$ & $\begin{array}{c}0000 \\
90 \star 0 \\
0000 \\
00 \bullet 0 \\
\text { (b1) }\end{array}$ & $\begin{array}{l}0000 \\
0 \bullet \bullet A \\
00 \bullet 0 \\
0 \bullet 00 \\
\text { (b2) }\end{array}$ & $\begin{array}{c}000 \\
0 \star 100 \\
0000 \\
000 \\
\text { (c) }\end{array}$ & $\begin{array}{l}0000 \\
0 * 00 \\
0 \bullet 00 \\
0000 \\
\text { (d) }\end{array}$ & $\begin{array}{c}\star 000 \\
000 \text { म } \\
0000 \\
0 \star 00 \\
\text { (e) }\end{array}$ & $\begin{array}{l}0 \bullet 00 \\
\star 000 \\
000 \text { म } \\
0 \bullet 00 \\
\text { (f) }\end{array}$ \\
\hline
\end{tabular}

Fig.1 Examples of feature polnts. (a) End of a line. (b1), (b2) Corners. (c) Junction point. (d) Cross point. (e) Middle point. (f) Arbitrary point on an Isolated clrcle, and middle point.

\section{FEATURE EXTRACTING NEURAL NETWORK}

\subsection{Blockdiagram}

Figure 2 shows a blockdlagram of a feature extracting neural network. A character is applied to the I-layer. In the F-layer, the end of a line is extracted in the $F$, network. Candldates for the corner, the junction point and the cross point are detected in the $F_{2}$ network. The $F_{3}$ network extracts the corner of 90 degrees consisting of dlagonal lines.

The TR-layer has one neural network, In which llnes of the pattern are traced starting from the feature points. By counting the number of traces starting from the same point, Its feature is determined. At the same time, the middle point is determined as a meeting point of two traces.

\subsection{Features Extracted in F-Layer}

In this paper, a pattern is assumed to be a fine pattern. In actuality, of course, some pre-processing is necessary to obtain a fine pattern.

The pattern is first applied to the I-layer, whose outputs are 1 or 0 . Connection weights wifis from the ith unit in the I-layer to the $j$ th unit in the F-layer are determined by

$$
W_{I F I S}= \begin{cases}8, & 1=\mathrm{J} \\ 1, & \text { adjoining units } \\ 0, & \text { otherwise. }\end{cases}
$$

A unit has 8 adjoining units, as shown in Fig.3.

\section{(a) F, Neural Network}

The end of a line is detected in the $F_{1}$ network, by controlling the unit to be active, when its input is equal to 9.

\section{(b) $F_{2}$ Neural network}

Candidates for Feature Points:

By using the connection welghts given by Eq.(1), the units, which locate on the right position or the adjoining positions of the feature points, have the maximum input. These units have at least three adjolning active units. Therefore, the unit is controlled to be actlve, when its input is equal to or greater than 11.

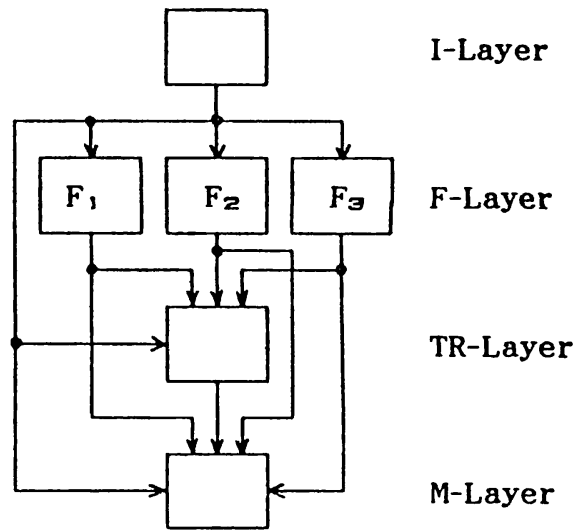

Fig.2 Blockdlagram for feature extracting neural network.

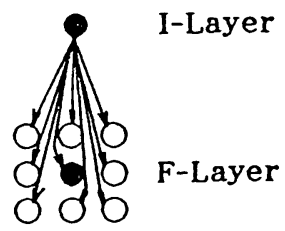

Fig. 3 Connectlons from Ilayer to F-layer. Unit has 8 adjoining units $\bigcirc$.

Examples are shown in Fig.4.

Competitive Learning:

Since several units can be active, in the initial state, an appropriate unit is selected through the following competitlve learning. Each unlt is connected with the adjolning unlts, and has a self-loop. Assuming the 1 th unit and the $j$ th unit locate in the adjoining, the input from the former to the latter is determined by

$$
u_{F Z 1 J}(n)= \begin{cases}\varepsilon, & v_{F Z J}(n-1)>v_{F 21}(n-1), \quad 1 \neq j, \quad n \geqq 1 \\ \delta, & v_{F 2 J}(n-1)=v_{F 2 I}(n-1) \\ -1, & v_{F Z J}(n-1)<v_{F 21}(n-1)\end{cases}
$$


where, $0<\varepsilon \ll \delta \ll 1$, and $v_{F Z_{1}}(n)$ and $v_{F 2 J}(n)$ are the outputs of both unlts. The InItlal output $\nabla_{\text {pas }}(0)$ is determined by

$$
\begin{aligned}
& \nabla_{F 2 J}(0)=\phi\left(\sum w_{1 F I J} v_{U}-10\right) \\
& \phi(x)= \begin{cases}x, & x>0 \\
0, & x \leqq 0\end{cases}
\end{aligned}
$$

where, $v_{u}$ is the output of the I-layer unlt. The $j$ th unlt output for $n \geqq 1$ is determined by

$$
\operatorname{vazj}_{\text {Fas }}(n)=\phi\left(\Sigma u_{\text {FaI }}(n)-\eta\right), n \geqq 1
$$

where $\eta$ is a random number $(0<\eta<\varepsilon)$, which makes small differences among the maximum inputs.

The unit, whose output is greater than that of the adjoining unit, can recelve positive input. On the contrary, the unit, whose output is less than that of the adjolning unit, recelves negative input. By repeating this state transition, the unlt, whlch has the maximum input at $n=0$, or locate on the central point of the cluster of the actlve units, can be the winner.

\section{(c) Fa Neural Network}

A corner of 90 degrees, consisting of dlagonal lines as shown in Fig.5, cannot be detected in the $F_{2}$ network. Because it has only two adjoining active units. The $F_{3}$ network is used for detecting thls kind of corners.

Figure 6 illustrates the units, which are connected with each other. The units $\star$ and $(0)$ locate on the same coordlnates in each layer. The intermedlate unlts $\diamond_{1} \sim \diamond_{4}$ are prepared for each unit $(0$. They recelve the outputs from a palr of two units ((1), (2)), (1), (3)), (2), (4)), and (3), (4)). respectively, through weights wiAlk $=1$. These units are controlled to be actlve, when thelr input is equal to 2 . Their output is 1 .

The unit $(9)$ recelves the outputs from the units $\downarrow$ and $\diamond_{k}$ through excitatory connections $W_{1 F 3 J}=8$ and $W_{A F 3 r J}=1$, respectively, and from the unlts $O$ in the I-layer through Inhibitory connections $w_{1 F a i d}=-8$. Thus, the input of the unit (9) becomes $8+1=9$, only when the unlt $\star$ is the corner, as shown in Fig.5. Therefore, the unit 0 is controlled to be active, only when its input is equal to 9.

\subsection{Trace along Pattern in TR-Layer}

The $F_{2}$ network selects only candidates for feature points, as mentloned previously. Their feature are determined in the TR-layer by tracing along the pattern starting from the candidates.

A network in the TR-layer is a mutually connected neural network. A unit is connected to its nelghborhood through connections wris. Furthermore, it recelves the outputs from the I-layer and the F-layer through connections $W_{1}$ TIs and WFTIs, respectively. They are determined by

$$
\begin{aligned}
& w_{\text {ITIS }}= \begin{cases}8, & 1=j \\
0, & 1 \neq j\end{cases} \\
& w_{\text {FTI }}= \begin{cases}1, & 1=\mathrm{J} \\
0, & 1 \neq j\end{cases} \\
& w_{\text {TIS }}= \begin{cases}1, & \text { adjoining units } \\
0, & \text { otherwise }\end{cases}
\end{aligned}
$$

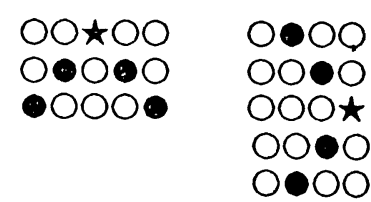

Fig. 5 Examples of corners $\star$. whlch have only two adjolning activated units.

$$
\begin{aligned}
& \text { (1) } \mathrm{O}(2) \\
& \mathrm{O} \times \mathrm{O} \\
& \text { (3) } \mathrm{O}(4) \\
& \diamond_{1} \diamond_{2} \diamond_{3} \diamond_{4} \begin{array}{c}
\text { Intermediate } \\
\text { units }
\end{array} \\
& \text { - ( ) - } \mathrm{F}_{3} \text { network }
\end{aligned}
$$

Fig. 6 Units In I-layer and F-layer, and Intermedlate unlts, which are connected in layer form.

$$
\begin{array}{cc}
\cdot 000,00 \cdot \cdot \text { I-Layer } \\
\cdot 00,0 \cdot & \text { F-Layer } \\
000 & \\
00,0 & \text { TR-Layer } \\
000 &
\end{array}
$$

Fig.7 Units in I-layer, F-layer and TR-layer, whlch are connected in layer form.

Figure 7 shows these relations. The unlts $O_{1}$, ( $)_{F}$ and $O_{T}$ locate on the same coordinates in each layer. The units $O$ in the TR-layer are the adjolning units of the unit $O_{T}$. In the Initlal state, the unit, which locates on the pattern, recelves 8 from the I-layer. Furthermore, if this unlt corresponds to the feature points, then it recelves 1 from the F-layer. Therefore, its input becomes $8+1=9$. By setting threshold to be 9 , only the feature units can be activated. They become starting units.

In the next step, the activated units output 1 to the adjoining units through the connections 
$W_{T I J}=1$. Therefore, input of the adjolning unlts, whlch locate on the pattern, becomes 9. Thus, unlt activation is propagated along lines of the pattern. In order to trace the lines with two active units, each unit stays in an active state during two time slots.

\subsection{Determining Features and Middle Points in M-Layer}

The end of a line, the corner, the junction point and the cross point have one, two, three and four traces, respectively. The number of the traces is detected in the M-layer. This layer recelves the outputs from the I-layer, the F-layer and the TR-layer, as shown In Fig.8. UnIts $\diamond_{1}, \diamond_{F}$, $\diamond_{T}$ and $\nabla_{M}$ locate on the same coordinates in each layer. Units $O_{D_{1}}, O_{D z}$ detect the traces, which include a pair of two active units. These units are prepared for possible directlons. They recelve the outputs from the active units (1) and (2), through connections wTDis=0.5 and wTDzis=1.5, respectively. By setting threshold to be 2, they become active, only when they detect the trace.

The unit $O_{F}$ is used for counting the number of traces. This unit recelves the outputs from the corresponding unit $\diamond_{F}$ in the F-layer and $O_{D K}$ through connections $W_{F F J}=10$ and $W_{D F K J}=1$, respectively. It is activated when its input is equal to or greater than 11. Its input represents the number of traces plus 10 , and is directly transferred to the unit $O_{M}$ in the $M$-layer.

The unit $O_{p}$ detects a middle point, at which two traces meet. This unit recelves the outputs from the F-layer $\diamond_{F}$ through large Inhibltory connections $W_{F P J}=-10$, in order to avold to select the feature point as a middle point. This unit also recelves the outputs from the I-layer $\diamond_{1}$, the TR-layer $\diamond_{T}$ and $O_{D x}$ through $W_{1 P J}=8$, WTPSJ 1 and WOPKJ $=1$, respectively. Furthermore, it recelves the output from the units $O$ in the TR-layer through inhibitory connections. This unit is activated when its input is equal to 10 , and outputs 10 to the unit $\diamond_{M}$ in the M-layer.

The unit $\diamond_{M}$ has two Inputs from the units $O_{F}$ and $O_{P}$. Thus, if its input is equal to 10, then the unit $\diamond_{M}$ represents the middle point. On the other hand, the input is equal to or greater than 11 , then the unit $\diamond_{M}$ stands for the feature polnt. A value, given by (the input - 10), is the number of traces, which determines the feature.

\subsection{Detection of Isolated Circle}

An Isolated clrcle, which does not have the prevlous features, is not detected in the F-layer. After the tracing in the TR-layer, one unlt of the clrcle is selected at random. The clrcle is traced starting from this unit, and the middle point is determined.

\section{FEATURE POINT DISTRIBUTION MAPPING}

\subsection{Seléction of Standard Patterns}

Let $P(m)$ and $Q$ be the standard and the distorted patterns, respectively. Thelr feature polnts are expressed by $(\boldsymbol{a}, \boldsymbol{\beta}, \cdot \cdot)$ and $(\mathbf{a}, \mathrm{b}, \cdot \cdot)$, respectlvely. $\alpha$ and a stand for the end of a llne, for Instance. Candidates of the standard patterns are selected based on the following similarity.

$$
\begin{aligned}
& s=\frac{\mathbf{p} \cdot \mathbf{q}}{|\mathbf{p}| \cdot|\mathbf{q}|} \\
& \mathbf{p}=[N(\boldsymbol{\alpha}), N(\boldsymbol{\beta}), N(\boldsymbol{\gamma}), \cdots] \\
& \mathbf{q}=[N(\mathbf{a}), N(\mathbf{b}), N(\mathbf{c}), \cdots]
\end{aligned}
$$

$N(\alpha)$ and $N(a)$ mean the number of feature points of $\boldsymbol{\alpha}$ and $a$, respectively. The numerator is an inner product of $\mathbf{p}$ and $\mathbf{q}$, and a symbol $\mid$ in the denominator stands for a norm of a vector.

\subsection{Modified Self-Organizing Feature Mapplng}

Feature polnts of both $\mathrm{P}(\mathrm{m})$ and $Q$ are distributed on the same plane. In order to simplify the following description, an $\mathrm{NxN}$ grid plane is used. Each feature point locates on the grid, which has the coordinates $(i, j)$. The feature point distribution of $P(m)$ is mapped on to that of $Q$. Because the standard patterns hold reasonable topological structure. This constralnt is used in the mapping. Stepl: A feature point is selected in the region, whose coordinates are $(1, j),(N, j),(1,1),(1, N), 1 \leqq$ $1, \mathrm{~J} \leqq N$. This region is called the 1st-region. An example is shown in Fig.9. The feature point is 
selected from both patterns, In order to avold vibration in the mapping process.

Step2: When a feature point $\alpha_{\mathrm{m}}$, which is an element of $\alpha$, Is selected, the corresponding feature polnt, whlch locates close to $\alpha_{m}$, is selected from $a$. Let this point be $a_{n}$. It can be found the outside of the 1st-region.

On the other hand, when $a_{n}$ is flrst selected in the 1st-reglon, then the corresponding $\alpha_{m}$ will be chosen from $\alpha$. The following processes are the same for both cases.

Step3: The feature polnts, which directly connected to $\alpha_{m}$ along the standard pattern, are selected as the neighborhood for $\alpha_{\mathrm{m}}$. We call these polnts 1st-order nelghborhood. The next feature polnts are called 2nd-order nelghborhood. Let rth-order nelghborhood be $\alpha_{\mathrm{mrk}}$.

Step4: $\alpha_{m}$ is shifted toward $a_{n}$ by a distance $d\left(\alpha_{m}\right)$. At the same time, the rth-order nelghborhood are shlfted toward the same direction by $\mathrm{d}\left(\alpha_{m r_{k}}\right)$. Shlfting distance is gradually decreased as $r$ increases as follows:

$$
\mathrm{d}\left(\alpha_{m}\right)>\mathrm{d}\left(\alpha_{m, k}\right)>\mathrm{d}\left(\alpha_{m 2 k}\right)>\text {. }
$$

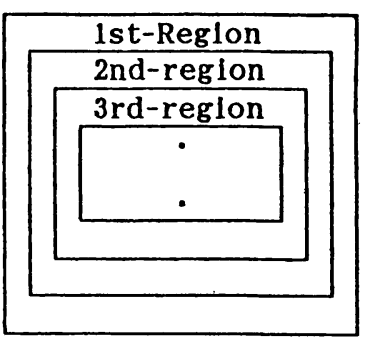

Fig.9 Varlable ring shape region, In which the feature point mapping is carrled out.

By using the nelghborhood, obtained in Step2, and the above welghted shifting distance, relative topological structure of $\mathrm{P}(\mathrm{m})$ can be held through the mapping.

Step5: Select another feature point in the same region, and repeat Step2 through Step4. If all feature points are selected in the 1st-reglon, then the mapping moves on the next reglon, that is the 2nd-region: $(2, J),(N-1, J),(1,2),(1, N-1), 2 \leqq 1, J \leqq N-1$. In thls reglon, Step 2 through Step4 are repeated. Thus, the mapping region is gradually reduced toward the central point, as shown in Fig.9. This variable region can make it possible to find out a sultable pairing of the feature points.

After the region reaches the central point, the mapplng process returns to Stepl. The above steps are repeated untll the mapping process converges.

\subsection{Pattern Recognition}

After the feature point mapping, the right character is selected using the following simllarity between the feature point distributions of the mapped version of $P(m)$ and $Q$.

$$
C=\frac{\left[\Sigma\left(\alpha_{m,} a_{n}\right) / r_{m n}\right]_{N}+[\beta]_{N}+[\gamma]_{N} \cdot}{\left[\Sigma\left(\alpha_{m}, a_{n}\right)+\sum \alpha_{m}+\sum a_{n}\right]_{D}+[\beta]_{D}+[\gamma]_{D} \cdot}
$$

In the above equation, each term is determined as follows: If $\alpha_{m}$ is exactly mapped onto $a_{n}$, then ( $\left.\alpha_{m}, a_{n}\right)=1, \alpha_{m}=0, a_{n}=0$ and $r_{m n}=1$. If $\alpha_{m}$ locates close to $a_{n}$, then $\left(\alpha_{m}, a_{n}\right)=1, \alpha_{m}=0, a_{n}=0$ and $r_{m n}>1$. $r_{m n}$ is proportional to the distance between $\alpha_{m}$ and $a_{n}$. If there is no corresponding feature point close to $\alpha_{m}$ and $a_{n}$, then $\left(\alpha_{m}, a_{n}\right)=0, \alpha_{m}=1$ and $a_{n}=1 . \quad[\beta] N, D$ and $[r] N, D$ Indicate the same operation as in the previous [] $\mathrm{N} . \mathrm{D}$ for $\alpha$ and $\mathrm{a}$. When the feature point distribution of $\mathrm{P}(\mathrm{m})$ is completely mapped onto that of $Q$, the simllarity $C$ becomes 1 . Otherwise, it is less than 1 .

\section{SIMULATION}

\subsection{Feature Extraction}

Alphabet and diglt characters in a printed form with $16 \times 16$ dots are used as the standard patterns. Flgure 10 shows examples of feature points extracted by the proposed neural network. A small point - Indicates a dot of the pattern. The middle points are not detected in a short line segments. This can be improved by increasing the number of dots. Although some feature points are somewhat shifted from their right positions, they can be compensated for in the modified SOM, as shown in the following.

\subsection{Feature Point Mapping}

An example of the distorted pattern and its feature points are shown in Fig.11. The candidates for thls pattern, selected based on Eq.(9), Include the patterns $r_{4}, r_{5}, r_{j}, Z_{\mathrm{J}}$ and $\mathrm{r}_{\mathrm{Z}}$. In order to shift the feature points continuously, a $32 \times 32$ grid plane is employed in this process.

Examples of the feature point mapping are shown In Fig.12 using ${ }^{\prime} N_{s},{ }^{\prime} Z$ s and ${ }^{\prime} 5$ s as the standard patterns. A solld line and a dotted line connect the feature points in the distorted and the mapped standard patterns, respectively. These lines do not exactly follow the patterns. The pattern iN, is exactly mapped onto its distorted version. The simllarlty $\mathrm{C}$ becomes 1 . On the other hand, the other patterns cannot approach to the distorted ${ }^{\prime} \mathrm{N}_{\jmath}$, due to their relative topological structure. 

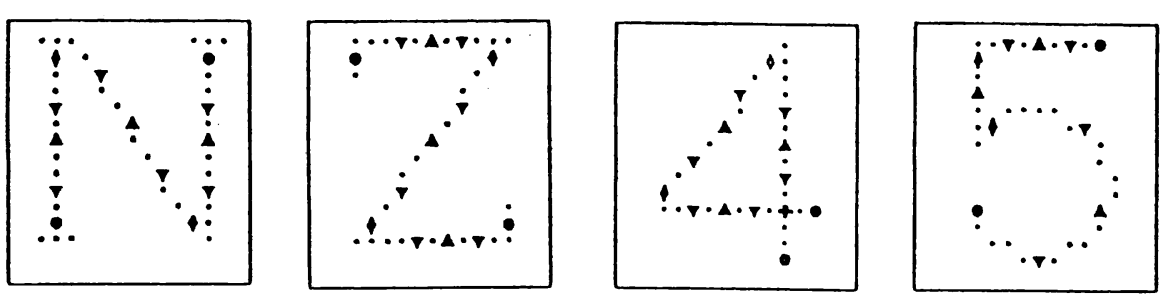

Fig.10 Examples of extracted feature points.

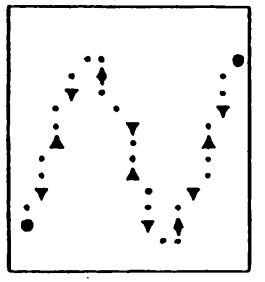

Fig.11 Distorted pattern of $\mathrm{N}$ s .
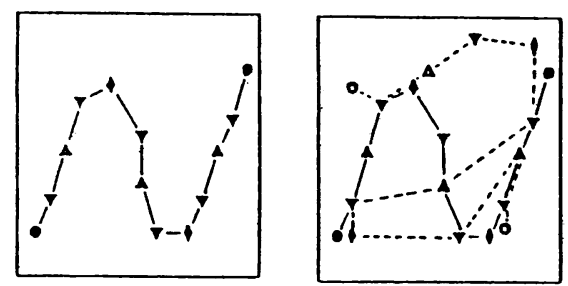
Fig.12 Examples of the feature point mapping.

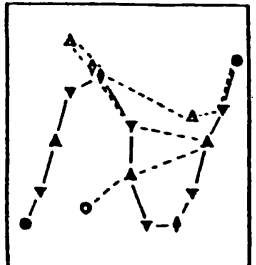

End of a line

Corner

T Junction polnt

+ Cross point

A Flrst middle polnt

$\nabla$ Second middle point

\subsection{Distorted Pattern Recognition}

We have tried so many distorted patterns. Flgure 13 shows some examples of patterns which can be recognized. From these results, the proposed method can adapt rotation, shifting, expansion and contraction and distortion, which can occur in the handwritten characters.
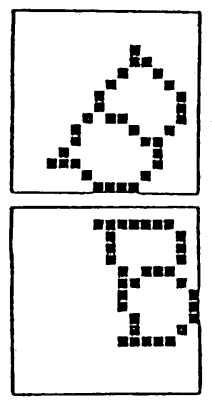
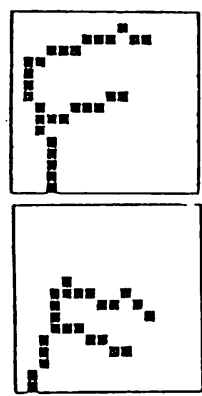
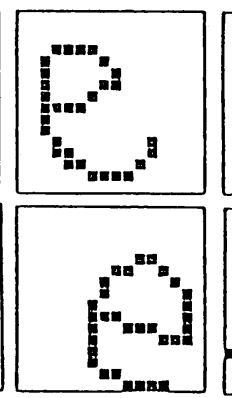
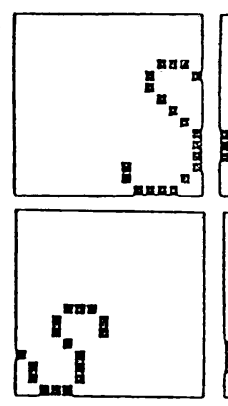
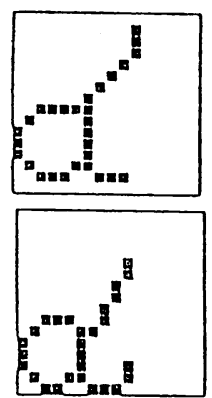
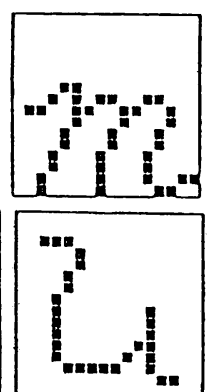

Fig.13 Examples of distorted characters, which can be recognized.

\section{CONCLUSIONS}

A new patten recognition scheme, based on neural networks, has been proposed for handwritten character recognition. Computer simulations have demonstrated the proposed method can adapt a variety of distortions. By adding typlcal handwritten characters in the standard patterns, more complicated and distorted patterns can be recognlzed.

\section{REFERENCES}

[1]K.Fukushima, S.Miyake and T.Ito, "Neocognitron: A neural network model for a mechanlsm of visual pattern recognition", IEEE Trans. vol.SMC-13, pp.826-834, 1983.

[2]Y.Chen et al., "Backpropagation applled to handwritten zip code recognition", Neural Network, vol.1, no.4, pp.541-551, 1989.

[3]Y.Hirai and Y.Tsukul, "Position Independent neuro pattern matching and Its application to handwritten numeral character recognition", Proc. IJCNN'91 San Diego, pp. III-695-701, 1991.

[4]T.P.Vogl et al., "Classification of hand-written diglts and Japanese Kanjl", Proc. IJCNN'91 Seattle, pp. I -97-102, 1991.

[5]S.Lee and J.Pan, "Handwritten numeral recognition based on hlerarchically self-organlzing learning networks", Proc. IJCNN' 91 Singapore, pp.1313-1322, 1991.

[6]Y.Idan and R.C.Chevallien, "Handwritten diglts recognition by a supervised Kohonen-11ke learning algorithm", Proc. IJCNN'91 Singapore, pp.2576-2581, 1991.

[7]Y. Chigawa, 0.Hasagawa and K. Nakayama, "Handwritten digit recognition by using feature extracting neural network and self-organlzing feature map". IEICE Japan, Report of Technical Meeting on Neuro Computing, vol.NC91-50, pp.15-22, 0ct. 1991.

[8]T.Kohonen, "The self-organizing map", Proc. IEEE, vol.78, no.9, pp.1464-1480, Sept. 1990. 